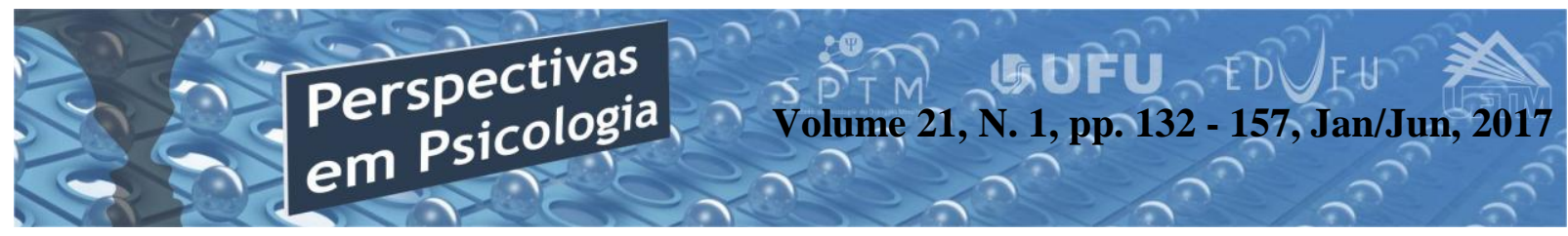

\title{
ENTREVISTA DE ANAMNESE DA TERAPIA DO ESQUEMA PARA CRIANÇAS: ANÁLISES E REFLEXÕES
}

\author{
Fabíola Rodrigues Matos \\ Renata Ferrarez Fernandes Lopes \\ (Universidade Federal de Uberlândia - UFU)
}

\begin{abstract}
Resumo
Esta pesquisa tem como objetivo analisar a entrevista de anamnese da Terapia do Esquema (TE), proposta por Loose, observando se é um instrumento adequado para elaboração de uma conceitualização de caso de acordo com os pressupostos da TE. A entrevista é composta por 12 perguntas, que objetivam investigar os recursos parentais e da criança. Observou-se que as perguntas são simples e objetivas, semi-estruturadas, avaliativas e categoriais. Há ênfase nas questões dedicadas à história da infância da criança na perspectiva dos pais e em EIDs presentes na história de vida dos mesmos. O roteiro permite hipotetizar a presença de EIDs, esquemas geracionais e modos de esquemas tanto nas crianças em seus primeiros anos de vida, como dos pais nesse mesmo período.
\end{abstract}

Palavras chave: anamnese; terapia do esquema para crianças; esquemas desadaptativos iniciais.

\section{Abstract \\ Schema Therapy for children's anamnesis interview: analysis and reflections}

This research aims to analyze the anamnesis interview of the Schema Therapy (TE), proposed by Loose, observing if it is an adequate instrument to elaborate a case conceptualization according to the TE presuppositions. The interview is composed of 12 questions, which aim to investigate the parental and child resources. It was observed that the questions are simple and objective, semi-structured, evaluative and categorical. There is an emphasis on the issues of children's history from the perspective of parents and from EIDs present in their children's life history. The script allows the hypothesis the presence of EIDs, generational schemas and schema modes in the children in their early years and parents in the same period.

Keywords: medical history; schema therapy for children; early maladaptive schemes.

\section{Introdução}

Em psicologia clínica, as sessões iniciais têm como objetivo avaliar o que está sendo apresentado pelo paciente como queixa e como isso o afeta. Nesse contexto são realizadas entrevistas que possuem como objetivo formular hipóteses 
diagnósticas para determinar as intervenções psicoterápicas que serão feitas ao longo do processo terapêutico (Affonso, 2005).

A anamnese é um instrumento crucial do diagnóstico psicológico, pois através dela pode-se obter informações relativas à história de vida do paciente, assim como dados sobre afetos, normas, preconceitos, expectativas, padrões familiares, problemas psiquiátricos pregressos, etc. (Ramos, 2011). Através da realização da anamnese será possível uma tomada de decisão em relação à escolha de quais instrumentos serão utilizados para o processo de investigação clínica (testes, escalas psicológicas, entre outros) avaliando-se a partir disso quais as intervenções psicoterapêuticas mais indicadas a serem oferecidas ao paciente (Affonso, 2005).

Sendo assim, uma entrevista psicológica pode ser de dois tipos fundamentais: a aberta (semi-estruturada) e a fechada (estruturada). Na entrevista semi-estruturada há uma maior flexibilidade, pois o entrevistador conduz o curso das perguntas de acordo com a necessidade e o caso. Já na entrevista estruturada há uma ordem quanto à maneira de formular as perguntas, que já estão previstas e não podem ser alteradas (Ramos, 2011).
Segundo Lopes e Lopes (2013), “a avaliação de uma criança em Terapia Cognitivo-Comportamental é um processo amplo que abrange a averiguação de informações de múltiplas fontes" (p.23). Os autores sugerem que uma boa anamnese é condição fundamental para uma adequada conceitualizacão de caso em Terapia Cognitivo-Comportamental, portanto ela deve ser ampla envolvendo informações de diferentes fontes tais como os pais, os familiares, os professores e a própria criança.

\section{Terapia do Esquema: EIDs, estratégias \\ de enfrentamento e teoria dos modos}

Os Esquemas Iniciais Desadaptativos: EIDs, conceito angular da Terapia do Esquema, são representações (esquemas) estáveis e duradouros que se desenvolvem precocemente perdurando ao longo da vida de uma pessoa e encontramse associados a diversas psicopatologias. São padrões emocionais e cognitivos desadaptativos que tendem a se repetir em determinadas experiências, modificando processos de funcionamento da personalidade que mediam a interação do indivíduo com a realidade (Cazassa, 2007; Lopes, 2015).

Os EIDs apresentam várias características definidoras que se 
destacam: são incondicionais; são resistentes à mudança; são disfuncionais de maneira significativa e recorrente; são ativados por acontecimentos ambientais aos quais o indivíduo é especialmente sensível; estão ligados a altos níveis de afeto; e resultam da interação entre o temperamento (inato) e as experiências disfuncionais nas relações familiares e sociais nos primeiros anos de vida (Duarte, Nunes \& Kristensen, 2008; Lopes, 2015). Quanto à origem dos EIDs é necessário salientar que resultam de necessidades emocionais não-satisfeitas na infância. Existem cinco necessidades emocionais fundamentais para os seres humanos: 1) Vínculos seguros com outros indivíduos (segurança, estabilidade, cuidado e aceitação); 2) Autonomia, competência e sentido de identidade; 3) Liberdade de expressão, necessidades e emoções válidas; 4) Espontaneidade e lazer; 5) Limites realistas e autocontrole. Tais necessidades parecem ser universais, sendo que algumas pessoas apresentam necessidades mais intensas do que outras, em função de aspectos diáticos (por exemplo, seu temperamento). Um indivíduo que consegue satisfazer de forma adaptativa as necessidades emocionais básicas é considerado psicologicamente saudável. O objetivo da Terapia do Esquema (TE) é, então, colaborar para que os pacientes encontrem formas adaptativas de satisfazer suas necessidades emocionais fundamentais que não foram adequadamente satisfeitas sejam eles crianças, adolescentes ou adultos (Loose, 2011; Lopes, 2015; Young, Klosko, \& Weishaar, 2008).

De acordo com Van Vreeswijk, Broersen e Nadort (2012), a Terapia do Esquema pressupõe a existência de 19 EIDs, sendo organizados em 5 domínios. O domínio I (desconexão e rejeição) engloba esquemas que se relacionam com sentimentos de frustração em relação à segurança, estabilidade, carinho, aceitação entre outros. Os esquemas presentes são: abandono/instabilidade, desconfiança/abuso, privação emocional, defectibilidade e isolamento social. Esquemas do domínio I podem ser originados por diversas causas, por exemplo, fatores que podem colaborar para o desenvolvimento do esquema de abandono/instabilidade: morte de um dos pais quando se era criança; separação da mãe por longos períodos de tempo na infância; pouca atenção dos pais (Young \& Klosko, 1994).

\section{O domínio II (autonomia e} desempenho prejudicados) agrega esquemas que se relacionam com a incapacidade de separação dos outros e com a deficiência de autonomia para sobreviver de modo independente. Os esquemas presentes nesse domínio são: 
dependência/incompetência,

vulnerabilidade ao dano ou à doença, emaranhamento/self subdesenvolvido e fracasso (Lopes \& Melo, 2014). Por exemplo, o esquema de vulnerabilidade ao dano ou à doença pode ter diversas origens: pais que foram superprotetores em relação a doenças ou que fizeram a criança se sentir muito frágil em relação à saúde. Também pode originar-se por condicionamento vicariante, no qual a criança aprende, por meio de observação de seus pais ou cuidadores, a temerem os mesmos estímulos que eles (Young \& Klosko, 1994).

O domínio III (limites prejudicados) engloba esquemas sobre a deficiência nos limites internos, ausência de responsabilidades, dificuldade em efetivar seus objetivos a longo prazo e prejuízo no respeito dos direitos dos outros. Estão presentes os esquemas de: arrogo/grandiosidade

e
autocontrole/autodisciplina insuficientes (Lopes \& Melo, 2014; Lopes, 2015; Young e outros, 2008). O esquema de arrogo/grandiosidade, por exemplo, pode se originar de relações com pais extremamente permissivos, que dão para a criança tudo que ela quer, no tempo em que ela deseja. A criança acaba controlando seus próprios pais (Young \& Klosko, 1994; Young e outros, 2008).
No domínio IV (direcionamento para o outro) há um foco excessivo nos desejos e sentimentos alheios, caracterizando-se por uma busca pela obtenção do amor e reconhecimento. Esse domínio engloba os esquemas de subjugação, autossacrifício e busca de aprovação/busca de reconhecimento (Lopes \& Melo, 2014; Young e outros, 2008). Tem-se como exemplo no esquema de subjugação, a suposição de algumas origens: o relacionamento com pais que procuram controlar todos os detalhes da vida da criança, que punem ou ficam bravos quando não conseguem as coisas do jeito deles ou com pais que não permitiram que a criança faça escolhas próprias subjugando-as (Young \& Klosko, 1994; Young e outros, 2008).

$\mathrm{O}$ domínio $\mathrm{V}$ (supervigilância e inibição) agrega esquemas que indicam bloqueios em relação à autoexpressão, à felicidade, ao relaxamento, aos relacionamentos íntimos e ao comprometimento em relação à própria saúde. Os esquemas presentes nesse domínio são de negatividade/pessimismo, inibição emocional, padrões inflexíveis/postura crítica exagerada e postura punitiva (Lopes \& Melo, 2014; Young e outros, 2008). A inibição emocional, por exemplo, pode originar-se na relação com pais frios, que não davam 
carinho/atenção ou que não se preocupavam com as necessidades da criança (Young \& Klosko, 1994).

Segundo Young e outros (2008), o modo como as pessoas se adaptam aos ambientes que não lhe oferecem acesso às necessidades básicas satisfatoriamente, levam ao desenvolvimento de respostas de enfrentamentos que podem ser desadaptativas e que são voltadas para perpetuação dos esquemas disfuncionais. Assim, são descritas três respostas básicas que correspondem aos estilos de enfrentamento: resignação (desistir de lutar contra o esquema, aceitando-o como verdadeiro), evitação (mecanismo de fuga do esquema, evitando a ativação do mesmo) e hipercompensação (luta contra o esquema, comportando-se e relacionandose como se o oposto do esquema fosse verdadeiro).

É importante destacar ainda o conceito de modos de esquema. Os modos de esquema são caracterizados como operações de esquemas, adaptativos ou desadaptativos, que estão ativos num dado momento, portanto caracterizam um "estado" do indivíduo, em outras palavras, um "estado dissociado". Foram identificados dez modos de esquemas, sendo agrupados em quatro categorias: modos criança, modos enfrentamento disfuncional, modos pais disfuncionais e modos adulto saudável (Young e outros, 2008).

Os modos criança são inatos, logo todas as crianças podem manifestá-los. Nessa categoria, incluem-se os modos: criança vulnerável, criança zangada, criança impulsiva e criança feliz. No modo criança vulnerável se manifestam esquemas de abandono, abuso, privação e rejeição. No modo criança zangada, a raiva está presente devido ao fato das necessidades emocionais não estarem sendo atendidas. Na criança impulsiva, observa-se que a criança age a partir dos seus desejos, sem pensar nas consequências dos seus comportamentos. Por fim, no modo criança feliz, o indivíduo sente que suas necessidades emocionais foram atendidas (Lopes, 2015; Young e outros, 2008).

Existem três modos na categoria modos de enfrentamento disfuncional: capitulador complacente, protetor desligado e hipercompensador. Esses três modos correspondem aos três estilos de enfrentamento de resignação, evitação e hipercompensação. Em relação à categoria modos pais disfuncionais são observados dois modos: pais punitivos e pais exigentes. Em tais modos, o indivíduo torna-se semelhante à mãe ou ao pai internalizado. No caso do modo pais punitivos, o indivíduo pune-se por se comportar mal, e no caso do modo pais 
exigentes, o modo ativo exige e pressiona o indivíduo a cumprir padrões demasiado elevados. Por fim, o último modo é caracterizado como adulto saudável, que é aquele buscado pela terapia. Assim, ensina-se ao paciente a sempre fortalecer seu modo adulto saudável, de forma que aprenda a moderar, lidar, cuidar ou neutralizar modos disfuncionais (Lopes, 2015; Young e outros, 2008).

\section{Modelo alemão da Terapia do Esquema}

Conforme Loose, Graaf e Zarbock (2013), são transmitidos de geração em geração os princípios, tradições familiares, normas, valores e estilos emocionais que constituem o relacionamento familiar. Pode então acontecer que os pais da criança em psicoterapia não tiveram suas próprias necessidades básicas supridas durante suas infâncias, colaborando assim para os mesmos não suprirem necessidades básicas do filho. Surge nesse contexto o conceito de coaching de esquemas, segundo o qual os esquemas dos pais se sobrepõem aos da criança, tornando o processo terapêutico mais desafiador. Os esquemas podem entrar em um círculo vicioso, pois considerando a dinâmica sistêmica geracional, os esquemas desadaptativos, modos e estilos de enfrentamento perpetuam-se nas gerações familiares sendo responsáveis pela frustração das necessidades básicas provocando os sintomas e comportamentos disfuncionais (Lopes, 2015; Loose e outros, 2013).

A qualidade do relacionamento da criança com o cuidador principal, determinado por padrões remotos de comportamentos e experiências dos pais é o fator ambiental mais importante para o desenvolvimento de uma criança saudável (Loose e outros, 2013). Torna-se fundamental esclarecer tais fatos aos pais dando-lhes uma visão ampla sobre o tipo de esquema que a família assimilou ao longo de gerações, visto que por meio da compreensão dos EIDs que foram desenvolvidos ao longo da história familiar é possível combater de forma mais eficaz tais esquemas, ajudando assim a criança (verdadeiro cliente da terapia infantil) a sentir e agir de uma forma mais criativa e saudável.

\section{A anamnese psicológica}

No método clínico, a entrevista é um instrumento essencial, sendo uma técnica de investigação científica em psicologia. Como técnica, ela possui seu método e regras empíricas próprias com as quais não só se amplia e apura um caso clínico, mas também permite o avanço do conhecimento científico quando o 
pesquisador se dedica a investigar $o$ alcance dessa técnica de investigação (Araújo e outros, 2013).

Tendo em vista os diferentes objetivos de uma entrevista inicial, destaca-se nesse trabalho aquele em que se busca conhecer com o maior número de detalhes a história de vida do paciente, esse tipo de entrevista é chamada de anamnese. O principal objetivo da anamnese é o levantamento do histórico do desenvolvimento do indivíduo. Ela representa um instrumento de grande importância, uma vez que permite ao psicólogo levantar suas hipóteses, identificar problemas, determinar diagnósticos, esquematizar ações de intervenções e acompanhar o progresso do paciente (Castoldi \& Scheffel, 2006).

\section{Entrevista semi-estruturada}

Todas as entrevistas, independente do objetivo que possuem, são realizadas para alcançar alguma finalidade, elas se dirigem para algum lugar, pois antes da realização de uma coleta de dados, é necessário saber claramente o que se deseja buscar sobre o objeto de estudo (Manzini, 2004). Em uma entrevista, é essencial que haja um planejamento da coleta de informações, pois são necessárias questões bem elaboradas que atinjam os objetivos pretendidos, levando em consideração as seguintes etapas: adequação da sequência de perguntas; elaboração de roteiros; necessidade de adequação de roteiros por meio de juízes; realização de projeto piloto para adequar o roteiro e a linguagem (Manzini, 2004).

Sabe-se que uma das características da entrevista semi-estruturada é a utilização de um roteiro previamente elaborado com perguntas básicas sobre o tema a ser investigado. De acordo com Triviños (1987), a entrevista semiestruturada caracteriza-se a partir de questionamentos que tem como base teorias e hipóteses que se relacionam ao tema da pesquisa. Tais questionamentos têm o objetivo de fazer surgir novas hipóteses por meio das respostas dos informantes. Dessa forma, esse tipo de entrevista favorece a descrição de fenômenos sociais, uma explicação e compreensão de sua totalidade, e também mantém a presença atuante do pesquisador no processo de coleta de informações, pois este pode ampliar seu horizonte de questionamento do interlocutor à medida que a entrevista avança. Uma entrevista semi-estruturada gira em torno de um assunto geral para o qual é construído um roteiro com perguntas principais, que podem ser complementadas por outras questões que estão ligadas às respostas dadas na entrevista. Esse tipo de entrevista colabora para trazer a tona informações de 


\section{ENTREVISTA DE ANAMNESE DA TERAPIA DO ESQUEMA PARA CRIANÇAS: ANÁLISES E REFLEXÕES}

um modo mais livre, sem haver uma padronização de respostas relacionadas a uma alternativa (Manzini, 1991).

Manzini (2003) destaca ainda que através da construção de um roteiro com perguntas que focalizam os objetivos pretendidos é possível haver uma melhor organização e planejamento para a interação do pesquisador com 0 informante. Triviños (1987), por sua vez, diferencia os tipos de pergunta da entrevista semi-estruturada de acordo com duas vertentes teóricas: fenomenológica ou histórico-estrutural (dialética). Na vertente fenomenológica, o objetivo é atingir a clareza nas descrições dos fenômenos sociais. Dessa forma as perguntas descritivas possuem grande importância para a descoberta dos significados dos comportamentos de indivíduos em certos ambientes culturais. Já na vertente histórico-cultural (dialética), as perguntas possuem teor mais explicativo ou causal. Esse tipo de pergunta tem como objetivo determinar razões imediatas ou mediatas do fenômeno social.

Triviños (1987) também distingue quatro tipos de categorias de perguntas: questões sobre consequências; questões avaliativas; questões hipotéticas; e questões categoriais. Tais categorias têm como objetivo abrir perspectivas para análise e interpretação de idéias. Manzini
(2003) alerta sobre a elaboração de roteiros para entrevista semi-estruturadas. Alguns cuidados são necessários na construção das questões para o entrevistado podendo-se citar: 1) Cuidados quanto à linguagem; 2) Cuidados quanto à forma das perguntas; e 3) Cuidados quanto à sequência das perguntas nos roteiros.

Utilizando-se como base o que foi apresentado sobre a importância de uma boa entrevista e do que deve ser feito para o alcance dos objetivos da mesma, foi realizada uma análise do roteiro da entrevista de anamnese para crianças desenvolvida por Loose (2011) para identificar a sua adequação em termos de linguagem, estrutura e sequência das perguntas no roteiro.

O objetivo dessa pesquisa teórica foi analisar as características do roteiro de entrevista semi-estruturada (anamnese), elaborada por Loose (2011) que avalia os esquemas desadaptativos iniciais e modos ativos nas crianças e nos pais que procuram psicoterapia para seus filhos, segundo a Terapia do Esquema. As características aqui analisadas foram: a) Se a entrevista utilizada é um instrumento adequado para elaboração de uma conceitualização de caso de acordo com os pressupostos da Terapia do Esquema alemã para crianças e b) Se o roteiro de perguntas corresponde aos objetivos da entrevista. 


\section{Método}

\section{Material}

O material usado nessa pesquisa foi uma entrevista desenvolvida por Loose (2011) e traduzida por Lopes (2015) que é utilizada como anamnese para investigação dos recursos parentais. O objetivo dessa entrevista é coletar informações sobre os primeiros anos de vida da criança e informações sobre a infância dos pais.

A entrevista contém 12 questões sendo todas voltadas à avaliação de possíveis Esquemas Iniciais
Desadaptativos e modos que estão presentes nos pais durante $\mathrm{o}$ desenvolvimento do filho. É importante destacar que para Loose e outros (2013), a sobreposição de esquemas entre pais e filhos é um dos impedimentos mais comuns para o bom andamento da Terapia do Esquema, decorrendo daí a necessidade de uma investigação aprofundada acerca da presença de EIDs e modos disfuncionais dos pais durante os primeiros anos de vida da criança (Lopes, 2015). As questões presentes na entrevista podem ser vistas na Tabela 1. 


\section{ENTREVISTA DE ANAMNESE DA TERAPIA DO ESQUEMA PARA CRIANÇAS: ANÁLISES E REFLEXÕES}

Tabela 1: Questões presentes na entrevista de anamnese de Loose (2011)

1-Com quanto tempo vocês souberam da gravidez? Período de tempo: ...

2-Como você classifica, a partir da perspectiva de hoje, a qualidade de seu relacionamento naquela época? (Por exemplo, amoroso, distante, ou similar)

3-Planejamento e desejo de gravidez: (sublinhe conforme o caso)

Mãe: a gravidez no geral: ocorreu no momento esperado, foi planejada, foi desejada, não foi desejada.

Pai: a gravidez no geral: ocorreu no momento esperado, foi planejada, foi desejada, não foi desejada.

4-Como a mãe passou durante a gravidez, tendo em vista a:

-Sua saúde corporal?

-Sua saúde mental?

Estresse psicológico ou algo similar?)

-Problemas com o parceiro (por exemplo, os conflitos aumentaram, houve alguma separação

-Consumo de nicotina e de drogas/álcool/outros?

-Houve outras fontes de estresse (por exemplo, problemas de ordem financeira, perda de emprego, sofreu ameaças, teve seus próprios pais doentes ...)

5-Como é que você experimentou, como mãe ou como pai, o nascimento da criança?

6-Do seu ponto de vista, você acredita que houve complicações durante ou após o parto? Você, por exemplo, ficou assustada?

7-Como você se sentiu nos dias e semanas logo após o nascimento da criança?

8-Você participou dos cuidados da criança nos primeiros dias e semanas após o nascimento?

9-Seu filho teve algum problema nos três primeiros meses de vida? (por exemplo, a dor, dificuldade de se alimentar, dificuldade de manter contato).

-Quanto tempo a criança foi amamentada?

-Houve complicações (por exemplo, dor, infecções no peito)? Se não ficou satisfeita (o), por quê?

10-Cuidador Primário/ Ajudante

0-3 meses

3-6 meses

6-12 meses

2 anos

3 anos

4 anos

5 anos

6 anos

(...)

11-As perguntas realizadas aos pais: Agora, por favor, descreva em termos gerais a sua infância. Por favor, liste três declarações típicas de sua mãe e/ou seu pai em sua infância.

12-Por favor, nomeie alguns atributos/adjetivos que refletem sua personalidade. Como você avalia seu atual estado mental (por exemplo, equilibrado, frágil, amedrontado, etc)? Como você mantém a sua própria saúde mental (hobbies, preferências, fontes de alimentação)?

$\mathrm{O}$ roteiro de entrevista de anamnese analisado nessa pesquisa envolve perguntas que cronologicamente remetem ao período em que os pais descobrem a gravidez, sobre a qualidade do relacionamento dos pais nessa época, o planejamento desta, como estava a saúde da mãe durante a gravidez, como foi vivenciado o nascimento do filho, aspectos da infância dos pais, entre outros. 


\section{Procedimento de análise}

As questões aqui analisadas são provenientes do roteiro de entrevista de anamnese proposto por Loose (2011). Duas frentes de investigação foram estabelecidas nesse trabalho teórico: Uma entrevista semi-estruturada, como a entrevista de anamnese analisada, é um instrumento adequado para elaboração de uma conceitualização de caso de acordo com os pressupostos da Terapia do Esquema alemã para crianças, especialmente no que tange ao conceito de sobreposição de esquemas paternos em relação aos EIDs dos filhos? O roteiro de perguntas corresponde aos objetivos da entrevista?

Para responder a primeira frente de investigação, foi adotado o seguinte procedimento de análise qualitativa: a) Análise das vantagens e desvantagens do uso da entrevista semi-estruturada a fim de se verificar se as vantagens alinham-se à proposta de conceitualização de caso na Terapia do Esquema para crianças; b) Considerando que uma entrevista semiestruturada supõe que o entrevistado e o entrevistador devam chegar a algum objetivo pré-determinado, analisou-se se as perguntas semi-estruturadas permitem alcançar o objetivo proposto no cabeçalho do instrumento analisado que visa esclarecer os objetivos da entrevista; c) Considerando que entrevistas semiestruturadas podem ser classificadas em perguntas sobre consequências, avaliativas, hipotéticas e categoriais, procedeu-se uma análise da categoria de cada uma das perguntas semi-estruturadas do roteiro.

Para responder a segunda frente de investigação: a) Avaliou-se se todas as perguntas são semi-estruturadas; b) Investigou-se se todas as perguntas são simples e objetivas; c) Examinou-se se a quantidade de perguntas no roteiro são adequadas e equilibradas frente aos objetivos da entrevista; d) Avaliou-se a natureza da sequência das perguntas no roteiro; e) Estabeleceu-se possíveis relações entre o tipo de pergunta semiaberta da anamnese e os aspectos teóricos da Terapia do Esquema para crianças da escola alemã.

\section{Resultados e Discussão}

Primeira frente de investigação: A anamnese da Terapia do Esquema para crianças segundo a escola alemã enquanto entrevista semi-estruturada.
A) Avaliação das vantagens $e$ desvantagens do uso da entrevista semi-estruturada da TE 


\section{ENTREVISTA DE ANAMNESE DA TERAPIA DO ESQUEMA PARA CRIANÇAS: ANÁLISES E REFLEXÕES}

Sabe-se que a entrevista semiestruturada viabiliza ao entrevistador discorrer sobre um determinado tema proposto, de uma forma em que ele siga um conjunto de questões previamente definidas, mas em um contexto mais livre, dando abertura para discussão sobre o que se responde. Esse tipo de possibilidade alinha-se perfeitamente ao conceito de conceitualização cognitiva estabelecido pela Terapia Cognitivo Comportamental e pela Terapia do Esquema.

Considerando que a anamnese compõe os instrumentos para se estabelecer uma conceitualização cognitiva adequada (Lopes \& Lopes, 2013), a estrutura do roteiro de anamnese proposto pela escola alemã parece ser vantajosa, tanto para fins clínicos, quanto para fins de pesquisa, para se atingir os objetivos pretendidos (conhecer os EIDs dos pais que se sobrepõem aos EIDs das crianças).

\section{B) Análise dos objetivos da anamnese da TE}

A entrevista de anamnese inicia com o seguinte cabeçalho: "Caros pais, a correta avaliação dos problemas do seu filho exige um conhecimento preciso dos primeiros anos de vida da criança e algumas informações da sua própria infância. Gostaríamos, portanto de pedir a sua ajuda.
Por favor não se acanhe em nos dar informações adicionais pois é necessário ampliar ao máximo nossa visão atual da criança. Sua informação é estritamente confidencial. Muito obrigado." (Loose, 2011).

Considerando que a entrevista tem como objetivo investigar de forma ampla os primeiros anos de vida da criança a luz de possíveis EIDs ativos nos pais naqueles períodos, assim como algumas informações da infância dos pais, pode-se afirmar que a entrevista cumpre seus objetivos. Na primeira parte da entrevista as questões buscam compreender de forma precisa todos os eventos que fizeram parte dos primeiros anos de vida da criança a luz da provável presença de EIDs paternos (cf. Tabela 1). A segunda parte busca coletar informações da infância dos pais, no momento em que esses EIDs poderiam ter surgido (cf. Tabela 1).

O roteiro permite com base nos dados oferecidos pelos entrevistados, hipotetizar a presença de EIDs tanto nas crianças ao longo de seus primeiros anos de vida, como de seus pais nesse mesmo período, esquemas geracionais e domínios de esquemas.

C) Classificação das perguntas semiestruturadas da anamnese da TE 
As perguntas presentes em uma entrevista semi-estruturada podem ser classificadas em quatro categorias diferentes: questões sobre consequências, questões avaliativas, questões hipotéticas e questões categoriais (Triviños, 1987). Na

Tabela 2 encontramos os tipos de questões que compõem o roteiro de anamnese.

Tabela 2: Classificação das questões semi-estruturadas que compõem a anamnese

\section{Questões}

"1-Com quanto tempo vocês souberam da gravidez?"
"2-Como você classifica, a partir da perspectiva de hoje, a qualidade de
seu relacionamento naquela época?(Por exemplo, amoroso, distante, ou
similar)"

"3-Planejamento e desejo de gravidez: Mãe: a gravidez no geral: ocorreu no momento esperado, foi planejada, foi desejada, não foi desejada. Pai: a gravidez no geral: ocorreu no momento esperado, foi planejada, foi desejada, não foi desejada"

\begin{abstract}
"4-Como a mãe passou durante a gravidez, tendo em vista a: sua saúde corporal? Sua saúde mental? Estresse psicológico? Problemas com o parceiro (por exemplo, os conflitos aumentaram, houve alguma separação ou algo similar?) Consumo de nicotina e de drogas / álcool / outros? Houve outras fontes de estresse (por exemplo, problemas de ordem financeira, perda de emprego, sofreu ameaças, teve seus próprios pais doentes...)"
\end{abstract}

"5-Como é que você experimentou, como mãe ou como pai, o nascimento Pergunta avaliativa da criança?"

"6-Do seu ponto de vista, você acredita que houve complicações durante Pergunta avaliativa ou após o parto? Você, por exemplo, ficou assustada (o)?"

"7-Como você se sentiu nos dias e semanas logo após o nascimento da Pergunta avaliativa criança?"

"8-Você participou dos cuidados da criança nos primeiros dias e Pergunta avalitativa semanas após o nascimento?"

"9-Seu filho teve algum problema nos três primeiros meses de vida? (por exemplo, a dor, dificuldade de se alimentar, dificuldade de manter contato). Quanto tempo a criança foi amamentada? Houve complicações (por exemplo, dor, infecções no peito)? Se não ficou satisfeita (o), por quê?"”

"10-Quem foi o cuidador primário/ajudante.

0 ---3 meses, etc

11-As perguntas realizadas aos pais:

"Agora, por favor, descreva em termos gerais a sua infância"

"Por favor, liste três declarações típicas de sua mãe elou seu pai em sua infância”

Pergunta categorial

Pergunta avaliativa

Pergunta avaliativa

Pergunta avaliativa
Classificação das questões semi-estruturadas (Triviños, 1987). categorial e categorial e

"12-Por favor,nomeie alguns atributos/adjetivos que refletem sua Pergunta avaliativa personalidade"

"Como você avalia seu atual estado mental (por exemplo, equilibrado, frágil, amedrontado, etc)?”

"Como você mantém a sua própria saúde mental (hobbies, preferências, fontes de alimentação)?” 
Dessa forma podemos concluir que a anamnese é predominantemente composta por perguntas avaliativas.

Com relação à segunda frente de investigação:

\section{A) Roteiro de perguntas e a semi- estruturação}

A entrevista de anamnese da Terapia do Esquema para crianças apresenta todas as características de uma entrevista semi-estruturada e a análise das perguntas separadamente corroboram $\mathrm{o}$ caráter de semi-estruturação (cf. Tabelas 1 e 2).

B) Análise da simplicidade $e$ objetividade das perguntas do roteiro

Segundo Manzini (2003), a formulação das questões de uma entrevista semi-estruturada deve ser realizada com um cuidado minucioso. Não deve haver perguntas arbitrárias, ambíguas, deslocadas ou tendenciosas. As perguntas devem ser feitas levando em conta a sequência do pensamento do entrevistado, ou seja, procurando dar continuidade na conversação, conduzindo a entrevista com um sentido lógico.
Após analisar as perguntas presentes na entrevista de anamnese da TE para crianças, pode-se afirmar que todas as questões são simples, objetivas, claras, breves e logicamente encadeadas, permitindo ao entrevistador obter várias respostas que favorecem a elaboração de hipóteses diagnósticas que se sustentam nos elementos principais da teoria que a subjaz.

\section{C) Análise da quantidade de perguntas}

A porcentagem de questões que aborda os diferentes temas da entrevista se deu da seguinte forma: Primeiros anos de vida da criança (21\%), nascimento (22\%), gestação (29\%), história da infância da criança (14\%) e história de vida dos pais (14\%).

Pode-se afirmar que há uma ênfase nas questões dedicadas à história da infância da criança pela perspectiva dos pais. Contudo $14 \%$ das questões são dedicadas a hipotetizar a natureza de EIDs presentes na história de vida dos pais. Conclui-se que a entrevista parece proporcional, pois permite avaliar a presença de EIDs e modos de esquema da criança e dos pais ao longo do desenvolvimento da criança. 
D) Análise da sequência das perguntas do roteiro

Analisou-se a sequência das perguntas da entrevista de anamnese a fim de confirmar se estas se distribuem de maneira a favorecer os objetivos da mesma. Observou-se que há uma lógica temporal, como se pode observar na Tabela 3:

Tabela 3: Sequência cronológica dos temas abordados na anamnese (Loose, 2011)

\begin{tabular}{cc}
\hline $\begin{array}{c}\text { Cronologia dos temas abordados na } \\
\text { entrevista }\end{array}$ & Questões \\
\hline Gravidez & $1,2,3,4$ \\
\hline Nascimento & $5,6,7$ \\
\hline Desenvolvimento infantil posterior & $8,9,10$ \\
\hline Questões ligadas a EIDs dos pais & 11,12 \\
\hline
\end{tabular}

Notou-se que as primeiras quatro perguntas dizem respeito à gravidez; as perguntas 5, 6 e 7, representam a época do nascimento e da experiência de ter uma nova criança em casa; as questões 8,9 e 10 são perguntas mais descritivas dos primeiros anos de vida da criança e, por fim, as questões 11 e 12 são ligadas as informações da infância dos pais buscando a identificação dos EIDs. Assim, pode-se afirmar que o roteiro da entrevista obedece uma sequência cronológica na disposição das perguntas.

E) Relação entre as perguntas do roteiro e aspectos teóricos da Terapia do Esquema para crianças segundo a escola alemã
Com quanto tempo vocês souberam da gravidez?

De acordo com Loose e outros (2013) alguns modos de esquemas dos pais podem ser ativados assim que estes passam a experimentar a maternidade/paternidade. Nesse contexto os modos de esquemas mais comuns são: adulto saudável, criança zangada, pais punitivos e exigentes, e também os modos de enfrentamento protetor desligado e hipercompensador (Lopes, 2015).

A questão realizada sobre a cronologia da descoberta da gravidez e os relatos em torno dessa descoberta possibilita investigar se algum desses modos estava ativo naquele momento, o que permitirá hipotetizar o funcionamento cognitivo-afetivo desses pais logo que souberam que teriam um filho. Nesse 
sentido, por exemplo, se os pais descrevem a notícia da gravidez de forma harmoniosa, hipotetiza-se a ativação do modo adulto saudável. Por sua vez, se o modo criança zangada esteve ativado estes pais poderiam descrever a gravidez como algo que frustrou suas necessidades e os sobrecarregou (Lopes, 2015).

Essa questão ainda permite hipotetizar EIDs ativos nos pais no momento da notícia da gravidez. Um exemplo seria uma mulher, que possui esquemas desadaptativos de desconexão e rejeição estabelecidos precocemente com os pais, ao saber da gravidez ela poderia se conectar intensamente e de forma patológica com o bebê (hipercompensação do esquema de abandono) ou poderia desconectar-se totalmente dele (manutenção do esquema de abandono), nutrindo em ambos os casos uma relação potencialmente prejudicial com a criança (Lopes, 2015).

Como você classifica, a partir da perspectiva de hoje, a qualidade de seu relacionamento naquela época? (Por exemplo, amoroso, distante, ou similar)

Em um relacionamento em que o casal possui um vínculo amoroso e estável, nota-se um convívio mais saudável, caracterizado pela confiança mútua, conforto e compaixão. Isso será projetado na relação com a criança futuramente, pois quando os pais são empáticos permitem a criança expor seus sentimentos em palavras e gestos favorecendo a satisfação da necessidade de liberdade de expressão e de emoções. Além disso, oferecem para si e para os filhos ambientes em que há previsibilidade nas interações. Por sua vez, um relacionamento em que a necessidade básica de autonomia entre os cônjuges não está sendo suprida, pode haver efeitos dessa desarmonia na relação com a criança, por exemplo, não proporcionando ao filho senso adequado de independência, da autoeficácia no ambiente familiar (Lopes, 2015).

Dessa forma, as repostas a essa questão da entrevista de anamnese dão uma descrição acerca das necessidades emocionais básicas atendidas ou não atendidas pelos parceiros durante a época em que a gravidez foi descoberta e, portanto, permite hipotetizar o tipo de atmosfera afetiva que havia no lar quando a criança nasceu (Young e outros, 2008).

Planejamento e desejo de gravidez: - Mãe: a gravidez no geral: ocorreu no momento esperado, foi planejada, foi desejada, não foi desejada. Pai: a gravidez no geral: ocorreu no momento esperado, foi planejada, foi desejada, não foi desejada 
De acordo com Young e outros (2008) os esquemas têm começo no início da infância ou na adolescência, como representações do ambiente da criança baseadas na realidade. Os esquemas pessoais refletem com precisão o clima do ambiente remoto. Como exemplo, Young e outros (2008) afirma que um paciente quando diz que na infância possuía uma família fria e pouco afetiva, geralmente ele tem razão ao relatar isso, mesmo que possa não entender, ou fazer atribuições falsas sobre o porquê seus pais apresentavam dificuldade de demonstrar afeto ou expressar sentimentos. Segundo os autores as razões por ele atribuídas aos sentimentos dos pais podem estar equivocadas, porém sua sensação sobre o clima emocional e sobre como foi tratado quase sempre é válida.

$\mathrm{O}$ sentimento que a criança tem sobre a frieza emocional dos pais pode ser causado por diversos motivos, entre eles, como a gravidez foi vivenciada pela mãe. Ao se ver grávida, a mãe pode ter ativado alguns EIDs que perduram durante toda a criação da criança, transmitindo então, sentimentos que esta pode perceber como distantes ou frios. Considerando os EIDs, a experiência da gravidez pode ser relacionada com diferentes domínios de esquemas.
No domínio $\mathrm{V}$, supervigilância e inibição, os esquemas pertencentes a ele podem ser ativados com uma gravidez não desejada, pois a mãe, ao saber-se grávida, pode se tornar extremamente preocupada e supervigilante aos eventos da vida. Dessa forma, a mãe pode desenvolver sentimentos de pressão constante e uma atitude crítica exagerada, impondo elevados padrões internalizados para si durante a gestação. Em relação ao pai, o mesmo pode acontecer, tendo em vista que seus EIDs também podem ser ativados com a notícia da gravidez e durante a gestação. O pai pode ativar os esquemas deste domínio, preocupando-se exageradamente com a proteção do filho e com o bem estar deste, dessa forma ele pode também criar padrões internos elevados sobre ser um bom pai. Ainda nesse domínio, observa-se que a frieza sentida pela criança na sua família de origem pode estar relacionada ao esquema de inibição emocional, na qual os pais restringem a expressão de sentimentos com o propósito de evitar críticas, sendo assim percebido pelo filho como indiferente ou frio.

Com relação ao domínio IV, direcionamento para o outro, os pais podem ver a gravidez como autossacrifício, no qual eles terão que cuidar das necessidades do outro (o filho) e esquecer as próprias necessidades, com a 


\section{ENTREVISTA DE ANAMNESE DA TERAPIA DO ESQUEMA PARA CRIANÇAS: ANÁLISES E REFLEXÕES}

intenção de evitar sentimentos de culpa. Com o nascimento do filho, a mãe precisa dedicar uma grande parte de seu tempo ao bebê e isso acarreta deixar de lado momentos do dia que tinha para si mesma. O pai também necessita abster-se de afazeres rotineiros para se dedicar ao filho que nasceu. Essas experiências podem ser vividas como fontes de sofrimento e preocupação (Lopes, 2015).

No domínio II, autonomia e desempenho prejudicados, a mãe pode ativar esquemas que a fazem pensar que é incapaz de suportar a dor do parto ou ter um medo exagerado que algo aconteça consigo e com o bebê, como complicações da gravidez/parto. O pai pode desenvolver esquemas que sejam relacionados a crenças de incapacidade de dar uma boa criação aos filhos e arcar com as responsabilidades que este fará surgir (Lopes, 2015).

Conclui-se que essa questão da entrevista de anamnese dá acesso a informações que permitem a compreensão das necessidades básicas dos pais que não foram atendidas na época da gravidez ou se os pais da criança compreenderam que a gestação seria um obstáculo em algum aspecto.

Como a mãe passou durante a gravidez, tendo em vista a: sua saúde corporal? Sua saúde mental? Estresse psicológico?
Problemas com o parceiro (por exemplo, os conflitos aumentaram, houve alguma separação ou algo similar?) Consumo de nicotina e de drogas/álcool/outros? Houve outras fontes de estresse (por exemplo, problemas de ordem financeira, perda de emprego, sofreu ameaças, teve seus próprios pais doentes...)

Considerando as necessidades básicas e a sua importância na vida de um indivíduo, observa-se que um dos pontos que esta questão busca compreender é como a mãe vivenciou os momentos da gestação, e se suas necessidades emocionais básicas foram atendidas nesse momento. Observa-se também que a questão permite à entrevistada indicar em sua narrativa a presença EIDs apenas falando sobre os cuidados com a saúde que tomou, ou não, nesse período.

Pode-se então investigar principalmente dois domínios: desconexão e rejeição e direcionamento para o outro. No domínio de desconexão e rejeição, esquemas geram sentimentos no indivíduo de que as suas necessidades de segurança, cuidado e respeito não serão atendidas. Assim, tais indivíduos possuem pais que foram frios, abusivos, rejeitadores ou individualistas. A falta de cuidado com a saúde, o abuso de álcool e de drogas durante a gestação pode apontar para esquemas do domínio de desconexão e 
rejeição ao bebê presente naquela etapa (Lopes, 2015).

Em relação a presença de EIDs do domínio de direcionamento para outro ativos durante a gestação pode-se inferir que a supressão de aspectos importantes da vida dos pais em vista da chegada do bebê, vivenciados como autosacrifício e busca de reconhecimento, podem gerar expectativas irrealistas sobre a chegada de um filho (Lopes, 2015).

Como é que você experimentou, como mãe ou como pai, o nascimento da criança?

Uma das fontes para a origem dos EIDs é o condicionamento vicariante estabelecido a partir da observação das figuras de apego (pais ou cuidadores). Segundo Young e outros (2008), uma das teorias do desenvolvimento humano que subjazem a Terapia do Esquema é a Teoria de Apego de Bowlby. Segundo Loose e outros (2013) a elaboração dos modos de enfrentamento bem como os modos pais punitivo/exigente, surgem a partir do condicionamento vicariante. Assim, as crianças observam os modos de enfrentamento dos pais frente a situações aversivas e tendem a reproduzi-los. Nesse sentido, se os pais lidam com suas experiências no papel materno e paterno usando defesas evitativas (modo protetor desligado), as crianças tendem a reproduzir as mesmas estratégias dos pais frente a situações de conflito (Lopes, 2015). Por sua vez, se os pais são exigentes e punitivos, a criança pode introjetar esse estilo de enfrentamento (exigente e punitivo) e vir a apresentar o modo pais exigentes. Logo, as respostas dos pais a essa questão podem ajudar a hipotetizar modos de esquemas presentes logo nos primeiros dias de vida que poderiam vir a modelar de maneira vicariante os modos apresentados pelas crianças explicando assim a natureza da queixa.

Do seu ponto de vista, você acredita que houve complicações durante ou após o parto? Você, por exemplo, ficou assustada?

Observa-se que esta pergunta é direcionada especificamente à mãe e avalia suas crenças em relação à experiência do parto. A forma como uma mãe percebe dificuldades presentes no parto, pode ser um indicador de ativação de um modo criança vulnerável, e do EID ligado à vulnerabilidade ao dano, já no momento do nascimento, especialmente se não houve nenhuma intercorrência grave durante o parto (Loose e outros, 2013; Lopes, 2015).

Dessa forma, medos de danos ou prejuízos físicos para si ou para a criança durante esse momento podem indicar a presença precoce de distorções cognitivas ligadas a catástrofes em termos de saúde, catástrofes emocionais ou catástrofes 


\section{ENTREVISTA DE ANAMNESE DA TERAPIA DO ESQUEMA PARA CRIANÇAS: ANÁLISES E REFLEXÕES}

externas, que perduraram mesmo depois do parto, ao longo dos primeiros anos de vida da criança, o que explicaria, por exemplo, queixas ligadas à ansiedade de separação na criança (Loose e outros, 2013).

Como você se sentiu nos dias e semanas logo após o nascimento da criança?

O nascimento de um filho traz para os pais responsabilidades, sentimentos e experiências que anteriormente não haviam vivenciado. Indagações se tornam frequentes durante esse período, como em relação à capacidade de cuidar do filho, dar segurança, proteção, etc. A presença de um filho na família torna-se então um desafio aos pais, acarreta sentimentos ambíguos que se alternam entre a alegria e o medo relacionado ao novo papel de ser pai/mãe. Os sentimentos surgidos nos primeiros dias e semanas logo após o nascimento do filho podem sugerir quais os pensamentos $\mathrm{e}$ sensações os pais experimentaram com a presença de um filho em suas vidas. Os bebês e seus comportamentos podem ativar nos pais diversos tipos de EIDs, assim como modos de esquema, que derivavam da frustração das necessidades emocionais básicas desses pais na infância.

Pode-se citar, por exemplo, EIDs do domínio de autonomia e desempenho prejudicados que podem levar os pais a superprotegerem excessivamente o bebê prejudicando a confiança da criança, uma vez que temem fracassar em sua tarefa de cuidador ou interpretam uma intensa vulnerabilidade ao dano evidenciada de maneira irrealística ao choro da criança. No caso da superproteção é possível inferir neste pai/mãe a ativação do modo pais exigentes e no caso da vulnerabilidade ao dano a ativação do modo criança vulnerável.

A questão nos permite ainda hipotetizar a presença de EIDs relacionados ao domínio de direcionamento para o outro na criança, quando seus pais afirmam ter colocado como prioridade seus próprios afazeres e vontades, indicando uma postura individualista. Esse padrão poderia desenvolver na criança um foco excessivo em cumprir as necessidades alheias em vez de suas próprias necessidades. Em relação aos modos, pode-se inferir a ativação do modo protetor desligado, quando após o nascimento, o pai ou a mãe utilizaram alguma estratégia evitativa gerando um desligamento afetivo em relação à criança, como em casos de depressão pós-parto. Outro modo que poderia estar ativado na depressão pós-parto seria o modo criança zangada que levaria a mãe a atitudes agressivas contra o bebê. 
Você participou dos cuidados da criança nos primeiros dias e semanas após o nascimento?

Sabe-se que os esquemas resultam de necessidades emocionais não satisfeitas na infância. Tais necessidades são universais, embora algumas se apresentem como necessidades mais fortes do que outras. Dessa forma, um indivíduo que se encontra psicologicamente saudável consegue satisfazer de forma adaptativa as necessidades emocionais fundamentais. A interação que existe entre o temperamento inato da criança e o primeiro ambiente tem como resultado a frustração, ao invés da gratificação, dessas necessidades básicas (Young e outros, 2008).

A gravidez pode colaborar para que as necessidades fundamentais do ser humano sejam supridas, porém ela também pode fazer com que tais necessidades não sejam solapadas. A participação ativa e saudável dos pais nos cuidados do bebê nos primeiros meses de vida é um indicativo de que a criança não frustrou necessidades básicas do casal, ao invés disso, pode ter suprido necessidades antigas como as de conexão, autonomia, competência, liberdade de expressão afetiva entre outras. Por sua vez a recusa de um dos pais de participar desse período inicial pode ser indicativo de ativação de EIDs ligados a desconexão e rejeição.
Seu filho teve algum problema nos três primeiros meses de vida? (por exemplo, dor, dificuldade de se alimentar, dificuldade de manter contato). Quanto tempo a criança foi amamentada? Houve complicações (por exemplo, dor ou infecções no peito)? Se não ficou satisfeita (o), por quê?

Tendo em vista as necessidades emocionais básicas que um indivíduo precisa ter para um desenvolvimento saudável, essa questão traz a tona uma investigação da relação pais-criança, analisando se tais necessidades estão sendo supridas ou não. Sabe-se que nos primeiros meses de vida da criança, a família precisa realizar adaptações significativas, como adquirir novos hábitos, regulação do sono, regulação da vigília do bebê, regulação do comportamento afetivo, desenvolvimento da atenção focalizada e busca pelo equilíbrio entre o vínculo profundo com a criança e a autonomia. Procura-se saber se os pais supriram as necessidades básicas da criança nos seus primeiros meses de vida, colaborando para o seu desenvolvimento saudável e se não frustraram suas próprias necessidades básicas.

Cuidador primário/ajudante, 0-3 meses, 36 meses, etc

De acordo com Young e outros (2008) existem quatro tipos de experiências no início da vida que 
estimulam o desenvolvimento de esquemas. A primeira experiência se trata de uma frustração nociva de necessidades, que ocorre quando a criança possui poucas experiências boas e adquire esquemas como privação emocional ou abandono por meio de déficits no ambiente, no início de sua vida. A criança não encontra (ou encontra muito pouco) no ambiente em que vive as sensações importantes como estabilidade, compreensão e amor. O segundo tipo é a traumatização ou vitimização. Nessa situação, algum dano é causado à criança ou ela se transforma em vítima, assim desenvolve esquemas como desconfiança/abuso,

defectividade/vergonha ou vulnerabilidade ao dano. No terceiro tipo de experiência, a criança possui uma grande quantidade de experiências boas, por exemplo, os pais proporcionam a ela algo em excesso que, moderadamente, seria saudável. Podem ser desenvolvidos então esquemas como dependência/incompetência ou arrogo/grandiosidade, em que a criança raramente é maltratada. A internalização ou identificação seletiva com pessoas importantes é o quarto tipo de experiência de vida que origina esquemas.

Deve-se lembrar que a criança ao nascer está em um ambiente onde há o cuidado dos pais, mas também pode haver a presença de diversos cuidadores.
Conforme Rapaport e Piccinini (2004), atualmente é frequente o retorno dos pais ao trabalho logo após os primeiros meses de vida do bebê, dessa forma é necessário que alguém cuide dele enquanto estes trabalham. Os cuidados alternativos (nãoparentais) podem ocorrer em: creches e pré-escolas; creche familiar (pequeno grupo de crianças na casa do cuidador); cuidado na casa da criança por uma babá/empregada; e, parente, na casa da criança ou na sua própria casa.

Dessa forma, os quatro tipos de experiências nocivas no início da vida que estimulam o desenvolvimento EIDs podem estar relacionados a outros cuidadores que participaram ativamente dos cuidados da criança ao longo dos primeiros anos de vida.

Agora, por favor, descreva em termos gerais a sua infância-Por favor, liste três declarações típicas de sua mãe elou seu pai em sua infância

A questão explora os EIDs e modos de esquemas presentes desde a infância dos pais. Por meio de frases típicas e apelidos que os pais receberam na infância pode-se hipotetizar a natureza das relações familiares deles e inferir possíveis EIDs e modos geracionais. Por exemplo: uma mãe ou pai que afirma ter ouvido repetidamente em sua infância: “engula o choro!”, podem 
ter desenvolvidos EIDs de privação emocional, privação de empatia, autossacrifício de necessidades, entre outros.

Com relação aos modos de esquema podem emergir o modos criança vulnerável que se autossacrifica para manter o amor aos pais e aos outros. Outro modo que pode se ativar é a criança zangada por ter que ceder aos outros (Loose e outros, 2013; Lopes, 2015). Esses pais poderiam exigir dos filhos a submissão de suas necessidades, como fizeram seus próprios pais, ou podem ficar zangados facilmente quando interpretam que seus filhos lhe fazem exigências que competem com suas necessidades (Lopes, 2015).

Por favor, nomeie alguns atributos/adjetivos que refletem sua personalidade. -Como você avalia seu atual estado mental (por exemplo, equilibrado, frágil, amedrontado, etc)? Como você mantém a sua própria saúde mental (hobbies, preferências, fontes de alimentação)?

As arguições sobre a saúde mental, física e sobre as necessidades de lazer permitem ao entrevistador avaliar se as necessidades básicas dos pais estão sendo atendidas atualmente. Permitem ainda avaliar se os pais criam condições para si próprios que permitem a ativação do modo adulto saudável ou se vivem contextos que favorecem modos desadaptativos que emergem de necessidades básicas solapadas (Loose e outros, 2013; Lopes, 2015).

\section{Considerações Finais}

Tendo em vista a importância das primeiras sessões e suas entrevistas iniciais, este trabalho buscou refletir e analisar, sobre as características da entrevista de anamnese da Terapia do Esquema para crianças da escola alemã. É necessário ressaltar que é por meio das entrevistas iniciais que é possível a formulação de hipóteses diagnósticas e determinação de investigações psicológicas a serem feitas durante a terapia.

Destaca-se que a entrevista de anamnese na abordagem da terapia do esquema envolve avaliar a partir de uma perspectiva cronológica a possibilidade de EIDs e modos de esquemas presentes nos pais e nas crianças, desde a concepção até a idade atual da criança. Por meio das informações pessoais dos pais é possível analisar tanto na criança quanto nos pais os esquemas iniciais desadaptativos, domínios de esquemas predominantes e modos de esquemas que podem estar presentes, levando essa família a ter pensamentos, emoções e comportamentos desadaptativos. 


\section{ENTREVISTA DE ANAMNESE DA TERAPIA DO ESQUEMA PARA CRIANÇAS: ANÁLISES E REFLEXÕES}

Além disso, a entrevista de anamnese avaliada permite verificar a sobreposição de esquemas, indicando que é uma entrevista bastante adequada aos pressupostos dessa abordagem, considerando não só os objetivos da própria entrevista, mas também os propósitos de uma entrevista semiestruturada. Este trabalho permitiu verificar que a entrevista associada a outros instrumentos de avaliação da abordagem, corrobora aos propósitos da Terapia do Esquema para crianças.
Dessa forma foi possível analisar e afirmar que, por meio das questões que foram aqui exploradas, os objetivos da entrevista de anamnese são coerentes com o que os pressupostos teóricos da Terapia do Esquema trazem. Futuras pesquisas poderão avaliar empiricamente o uso dessa entrevista para esclarecer a presença de esquemas iniciais desadaptativos, domínios e modos de esquemas.

\section{Referências}

Affonso, R. M. L. (2005). A importância da epistemologia no ensino da avaliação psicológica no processo psicodiagnóstico. Avaliação Psicológica, 4, 183-193.

Araújo, L. O., Feijó, L. P., Luz, I., Ernandez, C. C., Silva, J. D., \& Oliveira, D. S. (2013). Reflexão conceitual e empírica da importância dos intrumentos de entrevista inicial: anamnese e genograma. Anais Da VI Mostra Científica Do Cesuca. Cachoeirinhas-Rs, $1,1-12$.

Cazassa, M. J. (2007). Mapeamento de esquemas cognitivos: validação da versão brasileira do Young Schema Questionnaire - Short Form.(Dissertação De Mestrado). Pontifícia Universidade Católica Do Rio Grande Do Sul, Porto Alegre.

Cazassa, M. J., \& Oliveira, M. S. (2008). Terapia focada em esquemas: conceituação e pesquisas. Revista Psiquiatria Clínica, 35, 187-195. https://doi.org/10.1590/S010160832008000500003.

Castoldi, L., \& Scheffel, M. (2006). Prática em saúde no âmbito da clinica-escolar a teoria. São Paulo: Casa Do Psicólogo.

Duarte, A. L. C., Nunes, M. L. T., \& Kristensen, C. H. (2008). Esquemas Desadaptativos: revisão sistemática qualitativa. Revista Brasileira De Terapias Cognitivas, 4, 1-13. 
Loose, C. (2011). Schematherapy For Children. Disponível Em Http://Www.SchematherapyFor-Children.De. Acesso em 13 de março de 2015.

Loose, C., Graaf, P., \& Zarbock,G. 2013. Schematherapie Mit Kindern Und Jugendlichen. Basel: Beltz Verlag.

Lopes, R.F.F. (2015). Terapia do esquema em grupo com crianças e adolescentes. In: C. Neufeld (Org.), Terapia Cognitivo-Comportamental em grupo para crianças $e$ adolescentes (pp.102-128). Porto Alegre: Artmed.

Lopes. R.F.F., \& Lopes, E. J. L. (2013). Baralho Dos Problemas. Porto Alegre: Synopsis.

Lopes, J. B., \& Melo, W. V. (2014). A compreensão da repercussão dos esquemas iniciais desadaptativos, através da teoria dos esquemas, para otimização dos tratamentos de traumas. Revista Saúde E Desenvolvimento Humano, 2, 75-86.

Manzini, E. J. (1991). A Entrevista na Pesquisa Social. Didática, 26, 149-158.

Manzini, E. J. (2003). Considerações sobre a elaboração de roteiro para entrevista semiestruturada. In: M. C. Marquezine, M. A. Almeida, \& S. Omote. Colóquios sobre pesquisa em educação especial (pp.11-25). Londrina: Eduel.

Manzini, E.J. (2004). Entrevista semi-estruturada: análise de objetivos e de roteiros. Seminário internacional sobre pesquisa e estudos qualitativo, anais a pesquisa qualitativa em debate. Bauru-SP, 1,1-10.

Ramos, M. I. P. (2011). A Entrevista de anamnese sob a ótica do referencial teórico psicodramático: uma contribuição para a psicopedagogia. Revista Psicopedagogia, 28, 97-102.

Rapaport, A., Piccinini, C. A. (2011). Maternidade e situações estressantes no primeiro ano de vida do bebê. Psico-Usf, 16, 215-225. https://doi.org/10.1590/S141382712011000200010 .

Van Vreeswijk, M. F., Van, Broersen, J., \& Nadort, M. (2012). The Wiley-Blackwell Handbook Of Schematherapy, Theory, Research, And Practice. Oxford: WileyBlackwell. https://doi.org/10.1002/9781119962830.

Triviños, A. N. S. (1987). Introdução a pesquisa am ciências sociais: A pesquisa qualitativa em educação. São Paulo: Atlas.

Young, J. E., Klosko, J. S., \& Weishaar, M. E. (2008). Terapia do Esquema. Porto Alegre: Artmed.

Young, J. E., \& Klosko, J. S. (1994). Reiventing Your Life. New York: Plume Book. 


\section{ENTREVISTA DE ANAMNESE DA TERAPIA DO ESQUEMA PARA CRIANÇAS: ANÁLISES E REFLEXÕES}

\section{As autoras:}

Fabíola Rodrigues Matos é mestranda em Processos Cognitivos, na Psicologia pela Universidade Federal de Uberlândia (2016-2018), graduada em Psicologia pela Universidade Federal de Uberlândia (2015). E.mail: fabiolarmatos@yahoo.com.br

Renata Ferrarez Fernandes Lopes possui graduação em Psicologia pela Universidade de São Paulo (1993) e graduação em Teologia pela Faculdade Católica de Uberlândia (2013), mestrado em Psicobiologia pela Universidade de São Paulo (1996) e doutorado em Psicobiologia pela Universidade de São Paulo (1999). Atualmente é professora associada do Instituto de Psicologia da Universidade Federal de Uberlândia. Tem experiência na área de Psicologia, com ênfase em Psicoterapia Comportamental-Cognitiva para adultos e crianças. E.mail: rfernandeslopes@ fapsi.ufu.br

Recebido em: 25/05/2017.

Aprovado em: 23/06/2017. 